\title{
A comparison of the effects of physical and chemical mutagens in sesame (Sesamum indicum L.)
}

\author{
Tamina Begum and Tapash Dasgupta* \\ Department of Genetics and Plant Breeding, Institute of Agricultural Science, University of Calcutta, \\ Kolkata, India.
}

\begin{abstract}
Three sesame genotypes (Rama, SI 1666 and IC 21706) were treated with physical ( $\gamma$-rays: 200 Gy, 400 Gy or 600 Gy) or chemical (ethyl methane sulphonate, EMS: $0.5 \%, 1.0 \%, 1.5 \%$ or $2.0 \%$ ) mutagens and their mutagenic effectiveness and efficiency were estimated in the $\mathrm{M}_{2}$ generation. The $\mathrm{M}_{3}$ generation was used to identify the most effective mutagen and dose for induction of mutations. The average effectiveness of EMS was much higher than $\gamma$-rays. The lowest dose of $\gamma$-rays (200 Gy) and the lowest concentration of EMS $(0.5 \%)$ showed the highest mutagenic efficiency in all genotypes. Analysis of the $\mathrm{M}_{3}$ generation data based on parameters such as the variance ratio and the difference in residual variances derived from the model of Montalván and Ando indicated that $0.5 \%$ concentration of EMS was the most effective treatment for inducing mutations.
\end{abstract}

Key words: effectiveness, efficiency, mutagens, quantitative characters, sesame.

Received: October 30, 2009; Accepted: June 21, 2010.

The usefulness of any mutagen in plant breeding depends not only on its mutagenic effectiveness, but also on its mutagenic efficiency, efficient mutagenesis being the product of the maximum desirable changes accompanied by the least possible undesirable changes. Effectiveness and efficiency are two distinct properties of mutagens that have been extensively discussed elsewhere (Kawai, 1975, 1986; Shah et al., 2008; Girija and Dhanavel, 2009). While ionizing radiation still remains the most suitable means for inducing variability (Brunner, 1995; Bhatia et al., 2001; Irfaq and Nawab, 2003; Joseph et al., 2004; Sangsiri et al., 2005; Tah, 2006) a number of chemicals have been found to be equally and even many times more effective and efficient mutagens (Thakur and Sethi, 1995; Kharkwal, 1998; Solanki, 2005; Rekha and Langer, 2007; Basu et al., 2008, Dhanavel et al., 2008; Ganapathy et al., 2008; Wani, 2009). Effectiveness usually means the rate of point mutations relative to dose, whereas efficiency refers to the rate of point mutations relative to other biological effects induced by the mutagen and is considered a measure of damage (Konzak et al., 1965). Thus, two agents may be equal in mutagenic effectiveness because, at a given dose, they induce a mutation

Send correspondence to Tamina Begum. Department of Genetics and Plant Breeding, Institute of Agricultural Science, University of Calcutta, 35 Ballygunge Circular Road, 700019 Kolkata, India. E-mail: tamina@live.in.

*Present address: School of Biological Science, University of Aberdeen, Aberdeen AB24 3UU, UK. with the same frequency. However, when they diverge in their ability to produce undesirable changes such as sterility and lethality then they may be said to differ in mutagenic efficiency.

It is common practice to use only normal-looking $\mathrm{M}_{2}$ plants to obtain the $\mathrm{M}_{3}$ generation and apply preliminary visual selection in $\mathrm{M}_{3}$. This necessarily results in an increase in the volume of materials to be pursued and delays the isolation of promising variants. Consequently, considerable effort has been devoted to explore the possibility of selecting mutants with polygenic variability right from $\mathrm{M}_{2}$, which is the first generation to express variability after treatment. Moreover, the selection of promising variants in an early generation allows the rejection of unmutated "roughage" in $\mathrm{M}_{2}$. Obviously, mutagenic treatment is the sole cause of increasing variability in $\mathrm{M}_{2}$, especially considering that the check variety does not exhibit such variability. Further segregation of the polygenic system in $\mathrm{M}_{3}$ is expressed as the release of additional intrinsic variability. This being the mechanism of induction and inheritance of micromutations, selection in $\mathrm{M}_{2}$ or $\mathrm{M}_{3}$ can certainly help in identifying progenies that are likely to evince greater variability and a better response to selection.

The choice of effective mutagen and dose to be used (preferably one that induces enormous variability in any crop) is an important step. Montalván and Ando (2005) proposed a model to assess the effects of treatment on the mean 
and variance of mutagen-treated plants. Such an assessment could provide useful information for future sesame breeding programs.

In the present investigation, we examined the mutagenic effectiveness and efficiency of different doses of gamma $(\gamma)$-radiation and ethyl methane sulphonate (EMS) on the genetic variability of sesame in the $\mathrm{M}_{2}$ and $\mathrm{M}_{3}$ generations. The model of Montalván and Ando (2005) was applied to the $\mathrm{M}_{3}$ generation to identify the most effective mutagen and the dose that induced mutations.

Three sesame (Sesamum indicum L.) genotypes (Rama, SI 1666 and IC 21706) were selected for this study. One physical mutagen (gamma- or $\gamma$-rays) and a chemical mutagen (EMS) were used to induce mutations. Dry seeds (10\%-12\% moisture content) of each genotype were exposed to one of three doses (200 Gy, $400 \mathrm{~Gy}$ and $600 \mathrm{~Gy}$ ) of $\gamma$-rays derived from ${ }^{60} \mathrm{Co}$. Irradiation was done at the rate of $30 \mathrm{~Gy} / \mathrm{min}$ in the gamma garden of the Central Research Institute for Jute and Allied Fibres (CRIJAF) at Kolkata, West Bengal, India. Three hundred seeds per genotype were treated with each dose of radiation. In the case of EMS, seeds (150 per concentration) were exposed to one of four concentrations of the chemical $(0.5 \%, 1.0 \%$, $1.5 \%$ and $2.0 \%$ in phosphate buffer of neutral $\mathrm{pH}$ ) for $6 \mathrm{~h}$ with intermittent shaking. The treated seeds were then washed with water, dried with filter paper and immediately sown in the field. By the end of the experiments, each genotype had been subjected to eight treatments (control, three doses of $\gamma$-rays and four concentrations of EMS).

The seeds were sown at the end of February, 2004 at the Agricultural Experimental Farm of the University of Calcutta. The resulting plants were designated as $M_{1}$ plants and subsequently $\mathrm{M}_{2}$ and $\mathrm{M}_{3}$ plants were grown. The spacing between rows and plants was $35 \mathrm{~cm}$ and $10 \mathrm{~cm}$, respectively. A randomized block design was followed with three replications. Normal cultural practices were followed during the entire growing period. Mutagenic effectiveness and efficiency were estimated based on the relative frequency of family segregation in the $\mathrm{M}_{2}$ generation, as described by Konzak et al. (1965). Ten families were selected for the $\mathrm{M}_{3}$ generation based on their means. In $\mathrm{M}_{3}$, ten progeny rows were raised with a single control row for each treatment. The seeds were sown in the fourth week of February, 2006 in a randomized block design with three replications. The yield and yield components, i.e., plant height $(\mathrm{cm})$, number of branches per plant, number of capsules per plant, number of seeds per capsule, 1000-seed weight $(\mathrm{g})$ and seed yield per plant $(\mathrm{g})$ in the $\mathrm{M}_{3}$ generation were recorded.

The mean value, standard deviation, variance and coefficient of variation $(\mathrm{CV})$ for each trait were estimated.
The relative $\mathrm{CV}$ was estimated based on the $\mathrm{CV}$ of the mutagen-treated population $(\mathrm{CVt})$ and the non-treated control sample (CVnt), according to the method of Montalván and Ando (2005). The F-test was used to determine the significance of the increase in genetic variance attributed to mutagenic treatment, where

$$
\mathrm{F}=\frac{\text { Variance among treated plants }}{\text { Variance among control plants }}
$$

According to Ando and Vencovsky (1967), the difference between the residual variances of the treated and control samples provides an estimate of the increase in variance attributable to treatment with the mutagen and was computed as:

$$
\mathrm{Dt}=\mathrm{sr}^{2}-\mathrm{so}^{2}
$$

where Dt is the increase in variance attributable to treatment with the mutagen, $\mathrm{sr}^{2}$ is the residual variance resulting from treatment with the mutagen and $\mathrm{so}^{2}$ is the residual variance of the control.

The results for the $\mathrm{M}_{2}$ generation revealed that lower doses of mutagens were effective and efficient in causing polygenic variability in various quantitative characters, with a negative relationship between effectiveness and mutagen dose. These findings agreed with those of Roy Chowdhury et al. (2004) in mungbean, Dhanavel et al. (2008) in cowpea, Ganapathy et al. (2008) in little millet, and Sharma et al. (2005) and Thilagavathi and Mullainathan (2009) in black gram. The lowest concentration of EMS $(0.5 \%)$ was the most effective in causing mutations. The average effectiveness of EMS was several times higher than $\gamma$-rays. Among the genotypes, $0.5 \%$ EMS was most effective in SI 1666 compared to Rama and IC 21706. Interestingly, $\gamma$-rays were more efficient in inducing mutations, with a lower dose of $\gamma$-rays showing a higher mutagenic efficiency, regardless of the genotypes. Studies in wheat (Gaul and Aastveit, 1966), Arabidopsis thaliana (Brock, 1971) and cowpea (Girija and Dhanavel, 2009) have also shown that EMS is more effective than radiation in inducing polygenic variability. On the other hand, various studies have shown that ionizing radiation induces greater polygenic variability than chemical mutagens (Murty and Oropeza, 1989; Sorour et al., 1999; Larik et al., 2009) and is therefore a powerful tool for engendering such variability. The earlier findings are therefore inconclusive.

Ionizing radiations such as $\gamma$-rays are highly effective in inducing chromosomal aberrations (Nilan and Konzak, 1961) whereas mutagens such as EMS act primarily on base pairs of the DNA molecule and yield a higher number of gene mutations. Because of the basic mechanistic difference between these two groups of mutagens, chemical mutagens are generally considered to be superior to physi- 
cal mutagens for induction of mutation (Nilan and Konzak, 1961). Our findings for the $M_{2}$ generation generally agreed with this conclusion. The $\mathrm{M}_{3}$ generation was studied further to affirm the conclusion of $\mathrm{M}_{2}$ generation.

Analysis of the results for the $\mathrm{M}_{3}$ generation using the model of Montalván and Ando (2005) revealed important changes in the mean values of various traits in the treated groups of the three genotypes when compared to the controls. The highest percentage change caused by $\gamma$-rays $(244.16 \%)$ was observed in the number of branches per plant for SI 1666 seeds irradiated with $200 \mathrm{~Gy}$, whereas $0.5 \%$ EMS recorded maximum percentage change $(207.78 \%)$ for the number of capsules per plant derived from IC 21706 seeds (Table 1). The $\mathrm{CVt} / \mathrm{CVnt}$ ratio indicated that the $\gamma$-ray dose of 200 Gy was most effective in affecting the seed yield per plant and most of the yield components in irradiated population of Rama. On the other hand, a dose of 400 Gy was more effective in influencing the number of capsules per plant, 1000-seed weight and seed yield per plant in SI 1666 and IC 21706 (Table 1). Interestingly, the most effective EMS concentration varied among mutant populations, as indicated by the $\mathrm{CVt} / \mathrm{CVnt}$ ratio. Thus, $0.5 \%$ concentration of EMS was most effective in influencing the number of branches per plant, number of capsules per plant and seed yield per plant in all genotypes, whereas a concentration of $2.0 \%$ had a greater effect on plant height, number of seeds per capsule and 1000-seed weight in Rama plants; concentrations of $1.5 \%$ and $1.0 \%$ were more effective on these three parameters in SI 1666 and IC 21706 plants, respectively (Table 1).

There was a decrease in the coefficient of variation (CV) for all of the characters when data from individual plants (Table 1) rather than average data (Table 2) were considered. The highest CV (and correspondingly high standard error) was recorded for the number of branches per plant in SI 1666 plants exposed to 0.5\% EMS. Interestingly, the relative $\mathrm{CV}$ for the number of capsules per plant and number of seeds per capsule in mutant population of Rama, the number of branches per plant in mutants of SI 1666 , and plant height, number of branches per plant, number of capsules per plant, number of seeds per capsule and seed yield per plant in mutant population of IC 21706 was $>1.0$, indicating an increase in variance with these treatments (Table 1). The degree of variation in the number of capsules per plant was remarkably high in mutants of the three genotypes, but was low for 1000 -seed weight (Table 1). Among the different treatments, $0.5 \%$ EMS consistently produced greater variation in all of the characters except for plant height in Rama and SI 1666.

The increase in variance in the treated populations (Table 3) was an important indicator of the efficiency of the mutagen in inducing genetic variability. The F-test results showed that the mutagens were efficiently increased the variances of all of the traits except for 1000-seed weight (Table 3). The variance ratio (Vt/Vnt) was higher for all characters in plants from Rama seeds irradiated with 400 Gy and 600 Gy, whereas plants from SI 1666 and IC 21706 seeds exposed to 200 Gy and 600 Gy had higher F-variances for seed yield and many of the yield components. On the other hand, $0.5 \%$ EMS produced higher F-variances for the number of capsules per plant and seed yield per plant, regardless of the genotypes (Table 3). These findings further confirmed that these doses were more effective in producing variability. In general, the variance ratio was lower for 1000-seed weight when compared to other characters, regardless of the treatment.

A combined analysis of the different parameters, as proposed by Montalván and Ando (2005), suggested that $0.5 \%$ EMS was the best mutagenic treatment since it produced the greatest variability. This conclusion is drawn

Table 1 - Analysis of variance for six characters in the $M_{3}$ generation.

\begin{tabular}{|c|c|c|c|c|c|c|c|}
\hline Source of variation & df & Plant height & $\begin{array}{c}\text { Number of } \\
\text { branches/plant }\end{array}$ & $\begin{array}{c}\text { Number of } \\
\text { capsules/plant }\end{array}$ & $\begin{array}{c}\text { Number of } \\
\text { seeds/capsule }\end{array}$ & $\begin{array}{l}1000 \text {-seed } \\
\text { weight }\end{array}$ & $\begin{array}{c}\text { Seed } \\
\text { yield/plant }\end{array}$ \\
\hline Replication & 1 & 0.21 & 0.54 & 2.76 & 0.18 & 0.01 & 0.10 \\
\hline Variety & 2 & $24597.62 * *$ & $77.44 * *$ & $10464.08 * *$ & $300.69 * *$ & $0.10 * *$ & $386.04 * *$ \\
\hline Treatment & 7 & $4208.71 * *$ & $174.93 * *$ & $9668.57 * *$ & $186.19 * *$ & $0.10 * *$ & $337.77 * *$ \\
\hline Variety x Treatment & 14 & $2458.54 * *$ & $48.32 * *$ & $9412.63 * *$ & $103.50 * *$ & $0.14 * *$ & $386.37 * *$ \\
\hline Line & 9 & $404.30 * *$ & $22.55 * *$ & $1158.82 * *$ & $22.96 * *$ & $0.06 * *$ & $45.84 * *$ \\
\hline Variety $x$ Line & 18 & $295.70 * *$ & $32.18 * *$ & $892.02 * *$ & $20.80 * *$ & $0.03 * *$ & $33.29 * *$ \\
\hline Treatment $x$ Line & 63 & $446.29 * *$ & $25.71 * *$ & $2205.39 * *$ & $31.35 * *$ & $0.07 * *$ & $88.10^{* *}$ \\
\hline Variety $x$ Treatment $x$ Line & 126 & $511.79 * *$ & $27.13 * *$ & $2275.71 * *$ & $45.16^{* *}$ & $0.05 * *$ & $84.86 * *$ \\
\hline Errors & 239 & 1.19 & 0.65 & 4.35 & 0.33 & 0.002 & 0.15 \\
\hline $\mathrm{CV} \%$ & & 1.05 & 12.94 & 3.27 & 1.01 & 1.32 & 3.34 \\
\hline
\end{tabular}

$* * \mathrm{p}<0.01$, compared to control. 


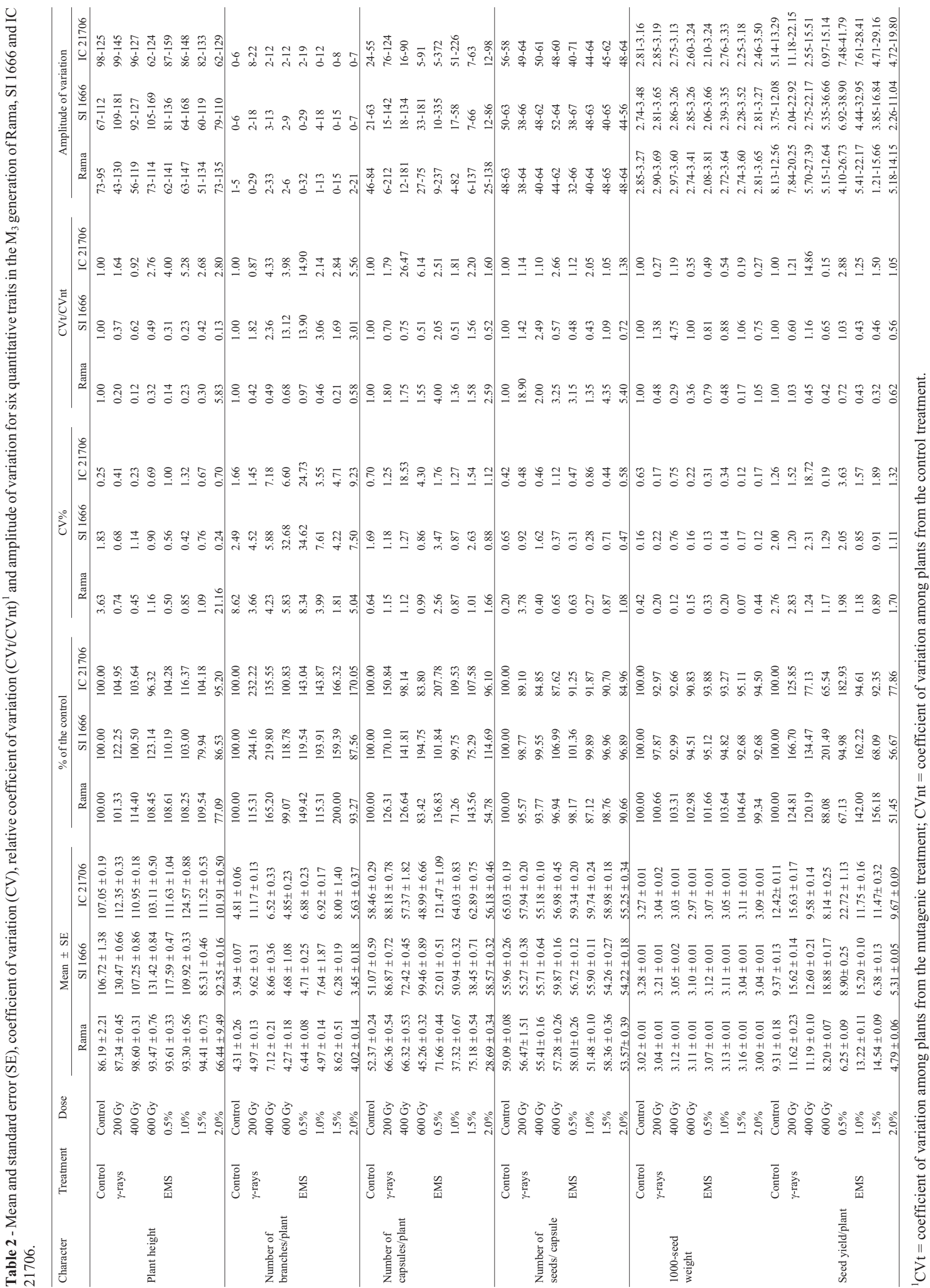


Table 3 - Phenotypic variance, residual variance, F-test $(\mathrm{Vt} / \mathrm{Vnt})^{1}$ and variance increase due to the mutagenic treatment (Dt) ${ }^{2}$, estimated for six quantitative characters in the $\mathrm{M}_{3}$ generation of Rama, SI 1666 and IC 21706 treated with $\gamma$-rays and EMS.

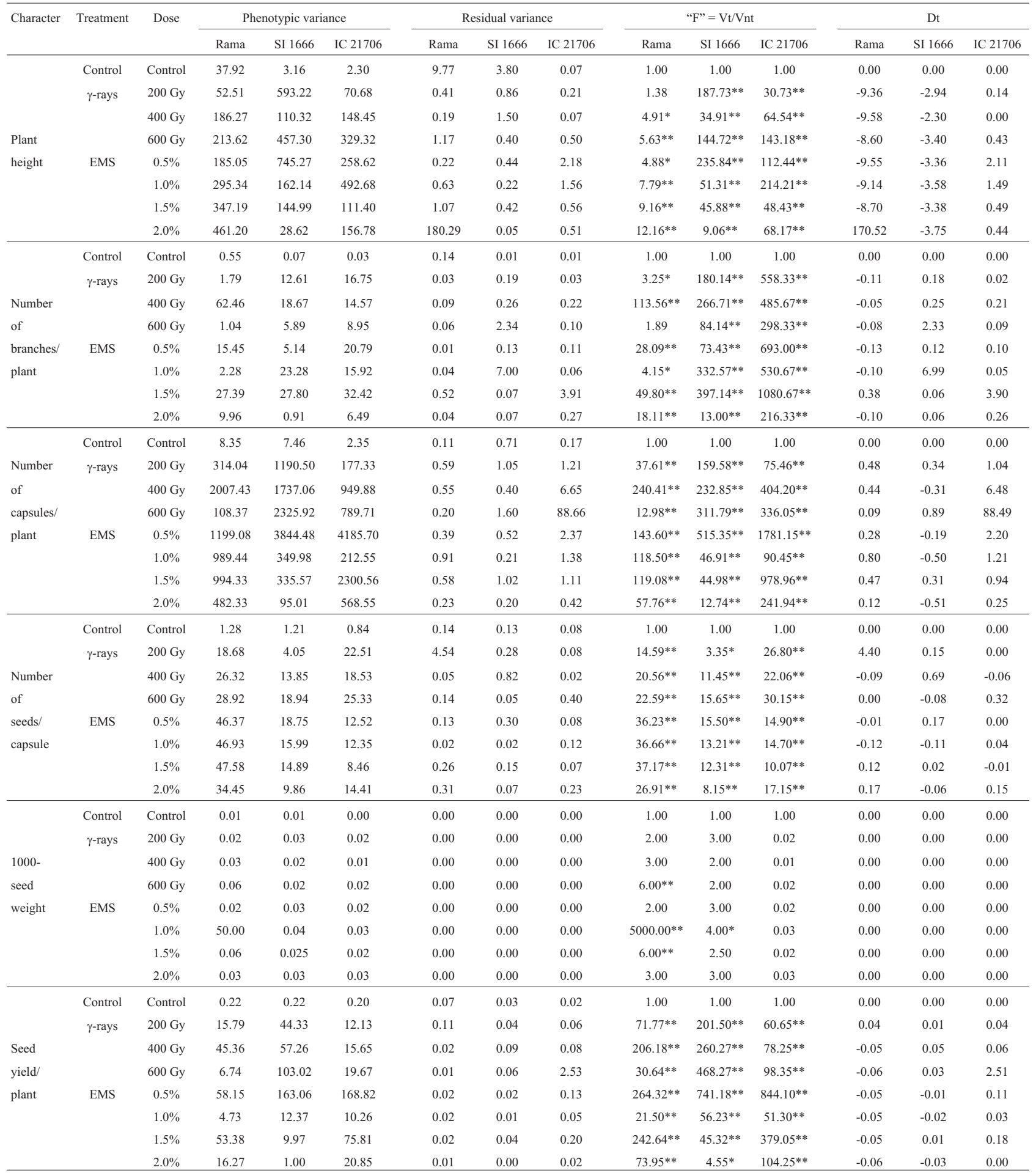

${ }^{1} \mathrm{Vt}=$ variance among mutagen-treated plants; Vnt $=$ variance among control plants.

${ }^{2} \mathrm{Dt}=\mathrm{sr}^{2}-\mathrm{so}^{2}$, where $\mathrm{sr}^{2}=$ variance increase due to the mutagenic treatment, $\mathrm{so}^{2}=$ control residual variance.

$* * * \mathrm{p}<0.05$ and $\mathrm{p}<0.01$, respectively, compared to control.

from the results regarding the effectiveness and efficiency of this concentration in the $\mathrm{M}_{2}$ generation. Overall, the results of this study indicate that the use of lower doses of chemical mutagens $(0.5 \%$ in the case of EMS $)$ that do not cause drastic chromosomal damage may be more effective in increasing the amount of variability. 


\section{Acknowledgments}

We are grateful to Prof. Ajit Das, Department of Agricultural Statistics, B.C. Agricultural University, West Bengal, India for his help in statistical analysis.

\section{References}

Ando A and Vencovsky R (1967) The effect of gamma-irradiation on a polygenically inherited character in Nicotiana tabacum L. in relation to selection after treatment of aged seeds. Mutat Res 4:605-614.

Basu SK, Acharya SH and Thomas EJ (2008) Genetic improvement of fenugreek (Trigonella foenum graecum L.) through EMS induced mutation breeding for higher seed yield under western Canada prairie conditions. Euphytica 160:249-258.

Bhatia CR, Maluszynski K, Nichterlin K and Zanten V (2001) Grain legume cultivars derived from induced mutations and mutations affecting nodulation. Mut Breed Rev 13:1-44.

Brock RD (1971) The role of induced mutations in plant improvement. Radiat Bot 11:181-196.

Brunner H (1995) Radiation induced mutations for plant selection. Appl Radiat Isot 46:589-594.

Dhanavel D, Pavadai P, Mullainathan L, Mohana D, Raju G, Girija $\mathrm{M}$ and Thilagavathi C (2008) Effectiveness and efficiency of chemical mutagens in cowpea (Vigna unguiculata (L.) Walp). Afr J Biotechnol 7:4116-4117.

Ganapathy S, Nirmalakumari A, Senthil N, Souframanien J and Raveendran TS (2008) Isolation of macromutations and mutagenic effectiveness and efficiency in little millet varieties. World J Agric Sci 4:483-486.

Gaul H and Aastveit K (1966) Induced variability of culm length in different genotypes of hexaploid wheat following X-irradiation and EMS treatment. Savrem Poljopr 11-12:263-276.

Girija M and Dhanavel D (2009) Mutagenic effectiveness and efficiency of gamma rays, ethyl methane sulphonate and their combined treatments in cowpea (Vigna unguiculata L. Walp). Global J Mol Sci 4:68-75.

Irfaq M and Nawab K (2003) A study to determine the proper dose of gamma radiation for inducing beneficial genetic variability in bread wheat (Triticum aestivum L.). Asian J Plant Sci 2:999-1003.

Joseph R, Yeoh HH and Loh CS (2004) Induced mutations in cassava using somatic embryos and identification of mutant plants with altered starch yield and composition. Plant Cell Rep 23:91-98.

Kawai T (1975) Factors affecting efficiency of selection of mutants in mutation breeding. Gamma Field Symp 14:1-10.

Kawai T (1986) Radiation breeding - 25 years and further on. Gamma Field Symp 25:1-36.

Kharkwal MC (1998) Induced mutations in chickpea (Cicer arietinum L.). I. Comparative mutagenic effectiveness and efficiency of physical and chemical mutagens. Indian J Genet 58:159-167.

Konzak CF, Nilan RA, Wagner J and Foster RJ (1965) Efficient chemical mutagenesis. Radiat Bot 5(Suppl):49-70.
Larik AS, Memon S and Soomro ZA (2009) Radiation induced polygenic mutations in Sorghum bicolor L. J Agric Res 47:11-19.

Montalván R and Ando A (2005) Effect of gamma-radiation and sodium azide on quantitative characters in rice (Oryza sativa L.). Genet Mol Biol 2:117-126.

Murty BR and Oropeza F (1989) Diversity pattern in Sesamum mutants selected for a semi-arid cropping system. Theor Appl Genet 77:275-286.

Nilan RA and Konzak CF (1961) Increasing the efficiency of mutation induction. In: Committee on Plant Breeding and Genetics of the Agricultural Board (eds) Mutation and Plant Breeding. Publication 891, National Academy of Sciences National Research Council, Washington DC, pp 437-460.

Rekha K and Langer A (2007) Induction and assessment of morpho-biochemical mutants in Artemisia pallens Bess. Genet Resourc Crop Evol 54:437-443.

Roy Chowdhury B, Dasgupta T, Das A and Das PK (2004) Gamma ray and ethyl methane sulphonate induced chlorophyll mutations in mungbean [Vigna radiata (L.) Wilczek]. Bangladesh j genet biotechnol 5:23-26.

Sangsiri C, Sorajjapinun W and Srinivesc P (2005) Gamma radiation induced mutations in mungbean. Sci Asia 31:251-255.

Shah TM, Mirza JI, Haq MA and Atta BM (2008) Induced genetic variability in chickpea (Cicer arietinum L.). II. Comparative mutagenic effectiveness and efficiency of physical and chemical mutagens. Pak J Bot 40:605-613.

Sharma SK, Ritu S and Pandey DP (2005) Studies on mutagen sensitivity, effectiveness and efficiency in urdbean [Vigna mungo (L.) Hepper]. Indian J Genet 65:20-22.

Solanki IS (2005) Isolation of macromutations and mutagenic effectiveness and efficiency in lentil (Lens culinaris Medik). Indian J Genet 65:264-268.

Sorour WAI, Hussein MH and EI-Imam MA (1999) Gamma-ray induced mutations in sesame (Sesamum indicum L.) I. Selection of useful mutants. Bull Fac Agric 50:516-531.

Tah PR (2006) Studies on gamma ray induced mutations in mungbean [Vigna radiata (L.) Wilczek]. Asian J Plant Sci 5:61-70.

Thakur JR and Sethi GS (1995) Comparative mutagenicity of gamma rays, ethyl methane sulphonate and sodium azide in barley (Hordeum vulgare L.). Crop Res 9:350-357.

Thilagavathi C and Mullainathan L (2009) Isolation of macro mutants and mutagenic effectiveness, efficiency in black gram [Vigna mungo (L) Hepper]. Global J Mol Sci 4:76-79.

Wani AA (2009) Mutagenic effectiveness and efficiency of gamma rays, ethyl methane sulphonate and their combination treatments in chickpea (Cicer arietinum L.). Asian J Plant Sci 8:318-321.

Associate Editor: Catarina S. Takahashi

License information: This is an open-access article distributed under the terms of the Creative Commons Attribution License, which permits unrestricted use, distribution, and reproduction in any medium, provided the original work is properly cited. 